\title{
A VISCOSITY RELAXED-EXTRAGRADIENT METHOD FOR MONOTONE VARIATIONAL INEQUALITIES AND FIXED POINT PROBLEMS
}

\author{
LU-CHUAN CENG ${ }^{1}$ AND JEN-CHIH YAO ${ }^{2}$
}

\begin{abstract}
In this paper we introduce a viscosity relaxed-extragradient method for finding a common element of the set of fixed points of a nonexpansive mapping and the set of solutions of the variational inequality problem for a monotone, Lipschitz-continuous mapping in a real Hilbert space $H$. The viscosity relaxed-extragradient method is based on two methods: extragradientlike approximation method and viscosity approximation method. We derive a weak convergence theorem for two sequences generated by this method. Utilizing this theorem we also construct an iterative process for finding a common zero of two mappings, one of which is a monotone, Lipschitz continuous mapping of $H$ into itself and the other taken from the more general class of maximal monotone mappings of $H$ into $2^{H}$.
\end{abstract}

Mathematics subject classification (2000): 47H09, 47J20.

Key words and phrases: Variational inequality, nonexpansive mapping, extragradient-like approximation method, viscosity approximation method, monotone mapping, fixed point, weak convergence, demiclosedness principle, Opial's condition.

\section{REFERENCES}

[1] F. E. BRowder AND W. V. PETRYShyn, Construction of fixed points of nonlinear mappings in Hilbert space, J. Math. Anal. Appl., 20 (1967), pp. 197-228.

[2] F. LIU AND M. Z. NASHED, Regularization of nonlinear ill-posed variational inequalities and convergence rates, Set-Valued Anal., 6 (1998), pp. 313-344.

[3] N. NADEZHKINA AND W. TAKAHASHI, Weak convergence theorem by an extragradient method for nonexpansive mappings and monotone mappings, J. Optim. Theory Appl., 128 (2006), pp. 191-201.

[4] W. TAKAHASHI AND M. TOYODA, Weak convergence theorems for nonexpansive mappings and monotone mappings, J. Optim. Theory Appl., 118 (2003), pp. 417-428.

[5] G. M. KoRPELEVICH, The extragradient method for finding saddle points and other problems, Matecon, 12 (1976), pp. 747-756.

[6] K. K. TAN AND H. K. XU, Approximating fixed points of nonexpansive mappings by the Ishikawa iteration process, J. Math. Anal. Appl., 178 (1993), pp. 301-308.

[7] R. T. ROCKAFELLAR, On the maximality of sums of nonlinear monotone operators, Trans. Amer. Math. Soc., 149 (1970), pp. 75-88.

[8] J. SCHU, Weak and strong convergence to fixed points of asymptotically nonexpansive mappings, Bull. Austra. Math. Soc., 43 (1991), pp. 153-159.

[9] I. YAMADA, The hybrid steepest-descent method for the variational inequality problem over the intersection of fixed-point sets of nonexpansive mappings, in Inherently Parallel Algorithms in Feasibility and Optimization and Their Applications, D. Butnariu, Y. Censor, and S. Reich, eds., Kluwer Academic, Dordrecht, The Netherlands, 2001, pp. 473-504.

[10] Z. OPIAL, Weak convergence of the sequence of successive approximations for nonexpansive mappings, Bull. Amer. Math. Soc., 73 (1967), pp. 591-597.

[11] L. C. CENG AND J. C. YAO, An extragradient-like approximation method for variational inequality problems and fixed point problems, Appl. Math. Comput., 190 (2007), pp. 205-215. 
[12] L. C. ZENG AND J. C. YAO, Strong convergence theorem by an extragradient method for fixed point problems and variational inequality problems, Taiwan. J. Math., 10 (5) (2006), pp. 1293-1303.

[13] K. Geobel AND W. A. KIRK, Topics on Metric Fixed-Point Theory, Cambridge University Press, Cambridge, England, 1990.

[14] R. GLOWINSKI, Numerical Methods for Nonlinear Variational Problems, Springer-Verlag, New York, 1984.

[15] B.-S. HE, Z.-H. YANG, AND X.-M. YUAN, An approximate proximal-extragradient type method for monotone variational inequalities, J. Math. Anal. Appl., 300 (2004), pp. 362-374.

[16] D. KINDERLEHRER AND G. STAMPACCHIA, An Introduction to Variational Inequalities and Their Applications, Academic Press, New York, 1980.

[17] L. C. ZENG, N. C. WONG, AND J. C. YAO, Convergence analysis of modified hybrid steepest-descent methods with variable parameters for variational inequalities, J. Optim. Theory Appl., 132 (2007), pp. 51-69.

[18] L. C. CENG AND J. C. YAO, Approximate proximal algorithms for generalized variational inequalities with pseudomonotone multifunctions, J. Comput. Appl. Math., (2007), doi: 10.1016/j.cam.2007.01.034.

[19] L. C. CENG AND J. C. YAO, On the convergence analysis of inexact hybrid extragradient proximal point algorithms for maximal monotone operators, J. Comput. Appl. Math., (2007), doi:10.1016/j.cam.2007.02.010.

[20] L. C. Zeng, N. C. Wong, AND J. C. YaO, Convergence of hybrid steepest-descent methods for generalized variational inequalities, Acta Math. Sinica, English Ser., 22 (1) (2006), pp. 1-12.

[21] H. K. XU, Viscosity approximation methods for nonexpansive mappings, J. Math. Anal. Appl., 298 (2004), pp. 279-291. 